\title{
Research on the Application of Situational Teaching Approach in Teaching Chinese as a Second Language
}

\author{
Kuerban•awuti \\ Xinjiang Institute of Light Industry Technology, Urumqi, 830021, China
}

\begin{abstract}
Keywords: Situational Teaching; Teaching Chinese as a Second Language(TCSL); Teaching Design
\end{abstract}

\begin{abstract}
Teaching Chinese as a Second Language(TCSL) is an important way to transmit the culture, which has played the role of bridge in Sino-Foreign cultural exchanges. However, while teaching Chinese as a second language, due to kind of factors, the teaching effects are not so ideal. Thus we need to explore new and scientific teaching mode based on the current situation of TCSL, further to construct a high-efficient TCSL classroom and give full play to the TCSL classroom as a bridge.
\end{abstract}

\section{Introduction}

With the implementation of reforming and opening up to the outside world, communication among all countries in the world has become more and more intimate. China has increasing influence on the world, thus the Chinese Breeze has spread all over the world and formed the "Chinese Rush". TCSL has also become an effective way to spread the excellent traditional culture of China. Situational teaching is the broadest way applied in TCSL. To apply the situational teaching method in TCSL classroom and improve the teaching quality and effects, teachers must make positive explorations, consistently improve the teaching mode and construct high-efficient classrooms.

\section{Connotations of Situational Teaching}

\section{Definition of Situational Teaching}

So-called situational teaching means that, teachers specifically design situations filled with subjective color and vivid images in the teaching process, so as to let students to be brought into the situations unconsciously and arouse psychological changes of students, further to obtain knowledge $^{[1]}$. In another word, situational teaching refers to that, during the teaching process, teachers can take advantage of pictures, videos, audios and other teaching tools to pass on teaching contents to students in a more intuitive and vivid way. Students can more easily and pleasurably internalize knowledge in classroom full of interest. The situational teaching mode can perform every aspect of TCSL, including pronunciation, vocabulary, grammar and dialogue. Thus it is helpful for TCSL to adopt a proper situational teaching mode.

\section{Effects of Situational Setting on Learning Chinese Language}

Effects of Pronunciation Teaching

To learn a language, foreign students start learning pronunciation first. Especially at the beginning stage, it is particularly crucial to learn pronunciation. In this period, teachers usually help students to better learn pronunciation by cards, place of articulation, sketch map of tone. Such as the figure of vowel lingual surface below, it is very efficient for the vowel teaching in TCSL. Students from some countries never contact the vowel ü[y] before, because it is the specific one in Chinese language. Students have difficulties to different extents when they pronounce the vowel. However, they have no difficulties in the vowel $i$. From the picture, we can see that $i$ and ü are different from each other in the aspect of shape of mouth and place of articulation. They can just pronounce after making some changes in the place of articulation by the tongue tip. In this way, students can more intuitively master the pronunciation and have systematical training, which is full of orderliness. 


\section{Effects of Vocabulary Teaching}

In teaching about vocabulary, there are usually many situations that teachers show pictures for students in teaching, thus they can learn vocabularies by judging and interpreting the contents of pictures. Teachers can also apply objects around them to teaching, especially in the contact with nouns at the preliminary stage. Teachers can teach the vocabularies of chair, blackboard and chalk in class. Students can also memorize nouns by observing the surrounding objects. Situational teaching stimulates students' interest and desire for learning, thus they can more subjectively learn new contents ${ }^{[2]}$.

\section{Effects of Sentence Grammar Teaching}

In the preliminary stage of learning Chinese language, students usually learn the sentences similar to "A is fatter than B". Teachers can select two students to make the comparison and students can quite directly see the difference between the student A and B. After making several comparisons, students can naturally master the sentence structure and grammar.

\section{Effects of Oral Communication}

In the part of oral communication, the setting of situational teaching mode just highlights its practical function. At the early beginning, the conversations are quite simple, such as inquiring for weather, orientation, making telephone calls. It is much easier to create the dialogues which are quite close to the living situations of students. Through setting situations, it makes the classroom full of interest, stimulates students' desire to learn, makes students to subjectively and positively join in the classroom and excises their ability to use the language. Moreover, by showing pictures and videos for students, it can stimulate students to develop from imaginary thinking to novel thinking, thus students can firmly grasp the contents they have learned in class. Relationship between teacher and student can become much closer and harmonious.

\section{Effects of Situational Teaching for TCSL}

\section{Being Conductive to Constructing High-efficient Classroom}

To learn and memorize language, people are not restricted to certain aspect. If sensory organs can be motivated, such as visual and auditory sense, learning language will be more rapid and profound. For instance, when students learn the vocabulary of "chair", if teachers just write the vocabulary on the blackboard, students can only mechanically memorize the blackboard-writing, but not understand the concrete meaning of "chair". But if teachers can provide all kinds of desk pictures and point out the chair students sit on, they can more intuitively learn the vocabulary of "chair”. In this way, it is much easier for students to learn. Just as we learn English, it will be much easier to learn the language after motivating factors of all aspects, further to improve the learning efficiency.

\section{To Avoid the Disadvantages of Traditional Methods of TCSL}

It is really difficult to learn language. Therefore, in the meanwhile of learning the Chinese language, foreign students also have to overcome the unfavorable influences of their own languages. In the preliminary learning, teachers usually adopt the way of constant repetition and consolidate the knowledge students have learned, which is usually mechanical and unitary. As time passes, students will generate negative mood because it is boring and difficult to learn the language. Even if they can persist in learning, their concentration may be reduced because it is really too dull, which leads to low learning efficiency. By adopting the situational teaching mode, it can arouse students' learning interest by creating different learning situations, who can internalize the knowledge points in class.

\section{Requirements of TCSL}

In recent years, with the consistent development of Chinese economy and reinforced international communication and cooperation, China has been demanded to accelerate the pace of cultural communication. Moreover, through communication with all countries, there are more and more people learning the Chinese language. Students have increasingly high qualities. As a consequence, it has also put forward new requirements for the teaching level of TCSL teachers; meanwhile, a lot of TCSL teacher groups have swarmed in China, thus competition among teachers has also become more and more fierce. Therefore, according to the requirements of the times and reality, the TCSL 
should also make proper reform and innovations and construct more efficient classrooms. In this way, it cannot only pass on knowledge to students, but also help them to keep good learning habits. Situational teaching both conforms to the requirements of times and teachers' requirements to improve their own qualities ${ }^{[3]}$.

\section{How to Create Situational Teaching Mode}

\section{Principles to Create Situational Teaching}

To apply the situational teaching method in the TCSL classrooms, it can stimulate students' interests to learn, activate the atmosphere of classroom and combine education with recreation. However, while developing the situational teaching method, it should follow the following principles:

Being Closely Related to the Teaching Contents

In the preliminary stage of learning language, students grasp limited vocabularies and grammars. In order to let them grasp knowledge points more firmly, it should fully understand the level of students at the present stage while designing the situational teaching mode, try to take the situations provided in the textbooks as the basis, and then make a few changes and innovations ${ }^{[4]}$. Thus students cannot only consolidate the contents of teaching materials, but also learn new knowledge points unconsciously. For instance, names of some countries appear in the first lesson of "Experience the Chinese Language--Life Chapter". If teachers can provide pictures, national flags and emblems of relevant countries, or representative pictures or videos of these countries, it will be much easier for students to learn the teaching contents. It can cultivate imagination of students, who can subjectively associate some objects with what they have learned in class.

Being Closely Related to the Reality of Life

Currently, students learning Chinese in China are usually composed of overseas students and business people. To live and learn in the big environment of China, they have to understand every aspect of the life. However, in the current teaching materials, the involved contents are still not comprehensive. There are also some missing details. But in the actual life, they have to use these knowledge. Students have quite strong desire for knowledge. Teachers should conform to the actual needs of students and changes of times, selectively create the situations closely related to the reality and apply vivid living environment to the classroom teaching. Thus students have more interests in learning and verify the teaching effects in the practicing life and will study more carefully in the next teaching.

\section{Being Related to Interest and Level of Students}

In the classroom teaching of TCSL, the composition of students is quite complicated. Students come from different countries, with different cultural foundations and living backgrounds. Therefore, while learning the Chinese language, interests and levels of students are not exactly the same. Teachers have to refer to the interests students perform in class and the actual situations of students while setting up the situations. For instance, if the student is on overseas one, the teacher can talk about the campus life with him. If the student is a middle-aged man from Russia, the teacher can set up a situation to explore the wine culture. If the level of students is still at the preliminary stage, the teacher should not be too anxious to set up quite difficult situations, which will frustrate the learning enthusiasm of students. On the contrary, when the ability of student is improved to a certain extent, the teacher should increase the difficulty of situations at the right moment.

\section{Concrete Setting Method of Situations}

\section{From Simple to Complex, From Easy to Difficult}

Because the language learning is a dynamic one, TCSL should also abide by such a law, fully considerate the stages that students are at, and then teach students from simple to complex, from easy to difficult, step by step ${ }^{[5]}$. In the very beginning, teachers can apply pictures and objects to help students to learn intuitively, and then increase the difficulty of setting situations in later stage, such as voices, videos, etc, and test what students have learned. In the final stage, teachers can bring students 
to the real life, who can apply what they have learned in class to the practice and then more directly understand the charm of language.

From Unitary to Complicated

According to learning contents in different stages, the difficulty of Chinese language is also different. In the preliminary stage, students usually learn nuns, such as names of fruits, stationary and clothes. Students are quite familiar with these vocabularies, who can frequently contact these things in life and can review them for many times. Thus it is quite easy to set the situations and students can well understand the teaching contents. With the constantly improvement of students' levels, teachers can increase the difficulty of situations and comprehensively apply many methods.

\section{Precautions for Implementing Situational Teaching Method}

Although application of situational teaching method in TCSL can fully motivate the enthusiasm of students and construct a more efficient classroom, it should also pay attention to the following problems:

\section{Not to be Led by Students}

Some teachers think that, the TCSL classroom should be dominated by the demands of students. Teachers should teach what students want to learn. In this way, it can satisfy the students' demands, and teachers no longer need to prepare the teaching contents. Such an idea is quite dangerous. Although demands and thoughts of students are important, teachers should teach students step by step, on the basis of characteristics and nature of TCSL. If some student overestimates his own strength, who demands to learn quite difficult link in the preliminary stage, the teacher should be responsible for the leaning of that student with love and make the student to learn the Chinese more comprehensively. Meanwhile, students can understand the charm of Chinese traditional culture contained in the Chinese language.

\section{Focusing on the Effects of Constant Practice}

To introduce the situational teaching to the TCSL classroom, although it can activate the atmosphere of classroom teaching, let students to master knowledge in a pleasurable atmosphere and understand those knowledge points more profoundly, the TCSL teaching should emphasize on the constant practice of knowledge points. The situational teaching method is just an auxiliary form of learning Chinese. It is most important to let students firmly grasp what they have learned by simple constant practice. To positively apply the situational teaching to the TCSL classroom, it just makes the classroom not to be dull any more, which is not the whole contents of classroom teaching.

\section{Paying Attention to the Individual Differences and Avoiding Communication Problems Led by Cultural Differences}

Students learning Chinese in the same classroom may come form different countries and regions, thus there are possibly some differences in the belief, religion and culture. Therefore, while setting up situations, teachers should consider the possible consequences led by cultural differences. Moreover, they should be capable of coping with contradictions that often happen calmly.

\section{Conclusion}

The teaching objects of TCSL are primarily students whose mother tongues are not Chinese language. Thus it is very useful to adopt the situational teaching in class, which may let students who learn Chinese to positively take part in the teaching activities of teachers, stimulate their enthusiasm for learning Chinese and make them take the initiative to learn the Chinese language. Rich situational teaching methods can let students to have fresh feeling in every class and learn much useful knowledge in the situational teaching, further to improve their level of Chinese language. During the teaching process of TCSL, teachers should combine the situational teaching method with other teaching methods and make efforts for improving the students' level of Chinese language. In this way, it can more efficiently construct high-efficient TCSL classrooms and spread Chinese culture better. 


\section{References}

[1] Yang Lihua. Primary Explorations of Situational Teaching in TCSL Classroom. Journal of Jilin Provincial Institute of Education(science edition), 2010,26(8):104-105.

[2] Xiang Jin. On the Comparative Situation Teaching in TCSL Classroom. Jin Tian, 2011,(9):152-153.

[3] Qiu Shiyuan, Tan Ling. Explorations of Comprehensive Situational Teaching in TCSL. Modern Chinese(Language Study), 2010, (12):125-126.

[4] Fan Lili.Humble Opinion about Situational Teaching in TCSL. New Campus(learning), 2012,(3):24.

[5] Cai Haiyan. Situational Teaching of TCSL Grammar and Pragmatics. Journal of Taizhou University (social science edition), 2005, 27(4): 34-36.

[6] Li Songmei. Brief Analysis on the Application of Situational Teaching in TCSL. Heihe Journal, 2013, (8):138-139. 